\title{
Leveraging Blogger Influence in the Launch of Storytel
}

\author{
Linn-Birgit Kampen Kristensen ${ }^{1}$
}

Published online: 4 May 2021

(C) The Author(s) 2021

\begin{abstract}
This article looks at three theoretical fields: communication theory based on the Two-step flow hypothesis, marketing theory concerning electronic word-of-mouth and finally diffusion theory of innovations. The launch of the audiobook streaming service Storytel in Norway is used as a case to describe the ramifications of only using bloggers in the introduction of a new service. The first research question is what factors are considered upon entering a brand relationship between product/service and blogger? The second research question is how do bloggers interact with their readers when participating in the launch of a new product/service? The article is based on qualitative interview with the marketing manager, contracts between influencers and audiobook streaming service in Norway, content analysis of blog posts and Instagram posts, and answers from a population survey to answer the question. This is a part of the Digitization and Diversity research project, conducted by the Centre for Creative Industries at BI Norwegian Business School, and is funded by the Norwegian Research Council under grant number: 247602.
\end{abstract}

Keywords Influencer marketing · Two-step communication · Innovation launch · Digital book services

\section{Introduction}

As digitalization of the Western world has grown, the opportunity for people to gather their opinions about various products and services online has grown [15]. Personal blogs appeared as a platform for individuals to discuss personal affairs, ideas and opinions [17]. The platform that bloggers use, have different attractiveness to various public relations activities [5, 37]. Previous research has found that bloggers have five characteristics that define them [16]. First bloggers update their blogs and publish them in reverse chronological order. They also include personal journal material, where the readers have an option to add comments, and the inclusion

Linn-Birgit Kampen Kristensen

linn-birgit.k.kristensen@bi.no

1 BI Norwegian Business School, NO-0442 Oslo, Norway 
of hyperlinks is more prominent than for other websites [16]. Furthermore, bloggers also use a human connection to emphasize their content. Bloggers use a human voice in the posts, and this is found to positively and significantly impact trust, satisfaction, commitment and control mutuality [22]. Research has also shown that bloggers are influenced in their creation of content [31]. Bloggers seek autonomy, but reader feedback that can serve as inspiration and validation of their work and they use pre-produced material from companies [31]. Authenticity is crucial for a blogger and by disclosing commercial collaboration in a blog post, bloggers risk losing some authenticity [1]. In order to maintain authenticity and trust in the blogger, creative constraints on the blog post should be removed by brand managers [1, 25]. Although we know much about the factors impacting trust and the importance of trust, we know little about how building trust regarding a new product via bloggers, and how the brand managers deals with the issues of authenticity. This article will look into how bloggers are used by brand managers and how the relationship between the blogger and brand manager can be structured and managed.

We know little about the role of bloggers in the introduction of new products or services, both when viewing it from the blogger's perspective and the readers' perspective. In addition, we know little about how the introduction process for products from the creative industries. The aim of the article is to investigate how bloggers can be used in the introduction of a new book streaming service.

The book industry in Norway is experiencing a shift, but not in the anticipated way with a conversion to e-books [28]. Increasingly more readers are utilizing audiobooks, and more specifically the streaming services for audiobooks [23]. Storytel was the first commercial actor on the Norwegian market that launched a book streaming service, and allowed Norwegian book readers to pay a monthly fee equal to other streaming services (e.g. Netflix, Spotify etc.) and gain unlimited access audiobooks and e-books from certain publishing houses [2]. A widespread service for book streaming had not yet entered the Norwegian market in 2014, and Storytel paved the way as a innovative new company in this field in Norway [19]. Storytel is partly owned by the Swedish establishing company Storytel AG and one of the three largest publishing houses in Norway, Cappelen-Damm. In addition to Storytel, the Norwegian market has gotten more book streaming services later. Fabel is the main competitor on the market now, and is currently owned by Lydbokforlaget AS, which in turn is owned by the two other largest publishing houses in NorwayAschehoug and Gyldendal [26]. As e-books has low usage in Norway with only 2 percent reading during an average day, and audiobooks are increasing with 4 percent to 6 percent during an average day [34], the natural question is "why?". When Storytel introduced itself to the Norwegian market, no traditional marketing was used [19]. Instead only bloggers were used to introduce the new service. With the launch of Storytel came the influence of bloggers as marketing tools very much to sight, but also as a person readers might have trust in, to give sound and good advice about books. By using Storytel as a case, the paper aims to describe how bloggers and social media can be used as the only marketing effort for diffusion of an innovation in a country with success. Who influences users when it comes to recommendations of books and how is the communication between blogger and reader? The overall research question for this paper is "what factors are considered upon entering 
a brand relationship between product/service and blogger"? The second research question is "how do bloggers interact with their readers when participating in the launch of a new product/service"?

The case of Storytel is chosen based on Storytel being the first service within creative industries to use a blogger strategy for marketing in the launch of the service in Norway. It is also the first and only international launch for Storytel that had a twostep communication and influencer strategy for diffusion and marketing. The article is structured with the theoretical framework, presentation of the case with Storytel, methodology, analysis, and discussion before conclusion.

\section{Theoretical Framework}

This article will draw upon three theoretical fields: Word-of-mouth and brand management, Two-step communication, and diffusion of innovations. These three academic areas are connected through bloggers as they execute all these marketing and communication efforts on their platform. The bloggers, through word-of-mouth [9], spread their views and opinions through the communication network equal to the two-step communication model [33] and by that contribute to diffusion of innovation [29]. The diffusion process is defined as "the process to which an innovation is communicated through certain channels over time among the members of a social system" [28, p. 35]. Innovations spread through social systems at different speeds, and innovations can be spread through traditional marketing, Word of Mouth, and/or a mix of the previous mentioned. The diffusion process can be used to explain why the traditional literature critic in mass media has declined to be almost non-existent in Norway at the current time. The two-step flow model presented by Katz and Lazarsfeld in 1955 established communication through opinion leaders and showed how efforts made in communication spread through social groups. This has been developed further to not only be used in traditional communication, but also in digital communication and with brand communication through digital tools.

\section{Word-of-Mouth and Brand Management}

Word-of-mouth (WOM) communication is a well-known term in marketing, and has a prominent position when influencing consumers purchasing decisions $[4,21]$. In the digital sphere, word-of-mouth transformed into electronic word-of-mouth (eWOM) as platforms for consumers to spread opinions grew [8, 15]. Previous research found that credibility of the source used for spreading of eWOM has an impact on the evaluation of the message $[8,13]$. Further, a negative eWOM message is more influential than positive eWOM. Prior knowledge and involvement are in some situations also shown to have moderating roles [8]. For eWOM on social media, quality and credibility of the information has a positive effect on the usefulness of the information, which next relates positively to information adoption [9].

Combined with the growth of personal bloggers, growth in eWOM has proven that brands no longer have single control over their brand [12]. Several studies find 
that blogger recommendations can provide positive eWOM for companies, and increase purchase intentions of the consumers [11,25]. Trust is also crucial for both the blogger and the company that have a cooperation with the bloger10. Consumers online behaviour impact the brand and marketing, and increasingly determine product/service diffusion process. Social media creates conversations and relationships between the consumers, and consumers and the company [12]. Bloggers have a target market segment that traditional marketing strategies cannot so easily unlock $[6,12,36]$. The benefits bloggers receive for speaking positively about the product or service on their blog can be split into two overall categories: indirect and direct monetary benefits [25]. In order to obtain credibility to their readers, some bloggers disclose the connection between the company and the blog [25]. When disclosing what monetary benefits the bloggers receive the consumers attitudes remain unaffected toward the blog post [25]. Readers of the blog post might also be skeptical of the content. When readers are met with a disclosure of collaboration with an "honest opinion" on the blog, the negative effects surrounding disclosure seem to disappear from both high and low levels of skeptisism toward the blog post [18]. Disclosing an endorsement as paid enhance the notion of openness and transparency of the influencer towards followers [6, 35]. As pointed out by Walden et al. [35] marketing managers should be honest and transparent in their communication to the bloggers, to improve the relationship between the parties.

\section{Two-Step Communication Theory and Marketing}

Katz and Lazarsfeld researched how one single person can be used to spread communication messages as early as 1955. The two-step flow model was originally developed for explaining opinion leadership during election campaigns. They found that individuals are subject to influence by others, and especially to those acting as intermediaries in the social interaction web. These intermediaries are opinion leaders. Furthermore, Katz and Larzarsfeld underline that the opinion leader must be perceived as prestigious to influence others (1955). Katz ([20], p. 73-75) defines the characteristics of opinions leaders; first, opinion leaders have the ability to express the personification of certain values. Second, they signal expertise in some area; and third, they have a social network that value their opinion and is of a certain size. The Decatur-study looked at how 800 female inhabitants of Decatur in Illinois underwent panel interviews to look at how they were influenced in their decision making. Specifically the study looked at how and who influenced the women and showed that personal influence and mass media have a relative impact in other realms, such as marketing [20]. Personal influence was more frequent and effective than any mass media in the Decatur study, and there was no concentration in socio-economic levels that could be found in the group members that was influenced by the opinion leaders [20]. Further, the Decatur study showed that opinion leaders in fashion were more exposed to the mass media and more affected by mass media in their (opinion leaders) decision [20].

In later years, the two-step flow model has been expanded to opinion leadership in other realms, and it has applied to study online communication and the 
digital sphere [3, 33]. Bloggers serve as new intermediaries for information about the world, and by that are attractive for disclosure of marketing communications. As for implementation of communication objectives from the brand to the consumer, the most common practice is to give bloggers monetary benefits, direct or indirect, for the blog post [14]. This leads to the question; how is the communication between bloggers and blogreaders manifested in the launch of Storytel?

Another aspect of two-step communication and opinion leadership is the position of what Rogers [29] terms change agents. As Rogers ([29], p. 27) points outchange agents use the social system of the opinion leaders to conduct their diffusion. A change agent differs from the opinion leader, as the change agent use the network created by an opinion leader and/or leads the message of the opinion leader. An opinion leader is a part of the system social system that change agents use to accelerate or decelerate the speed of diffusion. The role of the change agent can be divided into seven parts [29]. First, the change agent must create a need for change by showing alternatives to existing problems. Second, there is a need for information exchange between the client and target group for the client to be perceived as credible, trustworthy, and competent. Third, the change agent must look at solutions for the client that existing products or services do not solve for them. Fourth, an intent to change habit and by that an intent to use an innovation is created in the client. Fifth, the intent as described previously must be transformed into action. By changing intent to action the opinion leader can utilize its interpersonal network to spread the innovation. Sixth, the adoption must be stabilized, and the message conveyed in the interpersonal network needs to be repeated. This step is crucial for maintaining usage of the innovation and goes tightly with the seventh step of establishing a permanent relationship between the client and the innovation. These steps are ideals of how the change agent role should affect the client. Rogers points out that the change agent role is more connected to the clients' needs, its ability to manoeuvre between the interest of the client and the interest of the change agency [29]. Still, the success of the change agent is measured by the rate of how many members in the client interpersonal system is adopting the innovation. Therefore, another question is how does Storytel's role as a change agent manifest itself?

\section{Diffusion of Innovations and Marketing}

The definition of the diffusion process can be looked at from displacement of other technology as well [29]. As pointed out by Rosenberg (1972) the term displacement of "older" technology can be viewed as a historical process. In this process the displacement of a technique is a collection of small steps that can be tentative before one ends up with a new technology [30]. Within this, communication is key as it facilitates information sharing and mutual understanding. The diffusion then is communication where the message is about a new idea, service or product [29]. Furthermore, opinion leaders are persons within the social system that have influential power towards others. This influence can be used to indirectly or directly on others in a desired way [29]. According to Rogers what distinguishes opinion leaders from their followers are according to Rogers ([29], p. 27) the following three factors. 
Firstly, the opinion leaders expose themselves more in than followers in external communications. Secondly, socioeconomically status the opinion leaders is higher than the followers, and thirdly the opinion leaders tend to be more innovative. Also, there is a risk of over usage in opinion leaders as they are used too much in diffusion processes. Opinion leaders can be polymorphic in their opinion leader status or monomorphic [21, 29]. In a polymorphic state the individual acts as opinion leader in a variety of topics, and for monomorphism the individual is an opinion leader on a single topic [29]. The selection of opinion leaders is of key interest to in marketing and for the opinion leaders themselves [29].

The process of communication among members in a social system can have various forms. Still — who conveys the message to whom has an impact on the communication flow [29]. In this, the concept of homophily and heterophily are well known in marketing, communication, and innovation theory. For diffusion of innovations previous research has shown that homophily can act as a barrier within a system for the flow of innovation [29, p. 381]. Homophilous diffusion patterns may enable new ideas to spread horizontally, but act as barriers for ideas to spread or trickle down vertically. Ideally the diffusion should go vertically in order to gain momentum and by that increase speed of adoption of the innovation [29]. Rogers underlines that change agents usually are different from the clients but spends most time with the clients like themselves. In this there might be a discrepancy between those clients actually in need of a change agents help and those who gets it [29, p. 382].

\section{Case Presentation}

Blogging in Norway has become a multimillion business and grown from single bloggers posting on various platforms to bloggers organized in umbrella companies that support them (Rakeng 2016). The support bloggers receive is all from contracting to technical support and strategic planning. These support companies also provide the bloggers with legal guidance. This due to Norwegian law which requires bloggers to disclose any collaboration they enter and use for promotional purposes on the blog. Furthermore, there are taxation rules regarding sponsored products and collaborations [10]. The most successful bloggers earn millions a year in their operation of the blog and have several collaborations ongoing at the same time [7].

During the winter of 2014, the Swedish company Storytel launched their audiobook streaming service in the Norwegian market [19], but did not open for subscribers in the first period. Traditional marketing was not used in the launch of Storytel. Instead, Storytel cooperated with large three female bloggers, each with a daily reach of over 50,000 unique users, concentrating and targeting its marketing and communication toward readers of the blogs [19]. The blog posts were in some cases disclosed as sponsored posts, while others were not marked and did not include a disclosure of collaboration between the blogger and Storytel as a company. All initial posts included a story from the daily life of the blogger and how the audiobook-app fit with their life. The bloggers additionally borrowed the format of a book review to promote the service, and in some cases the bloggers recommended 
specific books but only on the app. The initial blogger contracts used varied from one post about the service to a yearlong contract between Storytel and the blogger.

The first blog post about Storytel is found in the mid-September 2015. This blog post does not disclose any collaboration between the blogger and Storytel. The same blogger posted a new entry with a disclosure of collaboration with Storytel only ten days after the initial post. Then this blogger is silent about Storytel, while other bloggers start posting about the app. One other large female blogger promoted Storytel in late November 2015. Another wave of blog posts about the app occurs in conjunction with Easter in 2016, and then the third wave is in conjunction with summer holiday of 2016. By the end of June 2016 there are four posts about Storytel on large female blogs in Norway. In the latter half of 2016, Storytel additionally involves two male bloggers in their marketing of the service. This is the only marketing efforts made by Storytel in the first year of practice in Norway, and the use of bloggers as marketing measure gets the newspapers attention in late autumn of 2016 [19]. The newspaper articles focus on the direct monetary means that the bloggers receive for one post about the app. In addition to direct monetary benefits bloggers receive, they also promote an indirect benefit that is shared with their readers: promotion code for free usage of the app for 30 days. Promotion codes are heavily used to spread offers around and trace a purchase to specific persons and/or websites [24].

\section{Methodology}

Empirically, this study is based on structured around four elements. First in-depth interview with Storytel's marketing manager in the introduction phase; secondly the briefs Storytel sent to bloggers, thirdly the Storytel-posts the bloggers published on the blog and Instagram, and fourth a population survey about books including questions about bloggers.

The key theme of the interviews is centered on the usage of bloggers in the promotion of Storytel, and how this affects the diffusion of the service in Norway. The material was analyzed using Nvivo 12. Briefs used by Storytel to the bloggers was analyzed simultaneously with the blog and Instagram posts. This to gain insight to how the posts were structured according to the briefs and looking at discrepancies between the brief and actual blog post. Furthermore, the bloggers use of disclosure in posts about Storytel and the consciousness surrounding disclosure of collaborations is also explored. Underlying material provided to the bloggers when approaching a collaboration with Storytel, has been made available for analysis in this study. The bloggers used for analysis here was a part of the introduction period of Storytel in Norway. In time, this is blog posts between late autumn 2015 to Christmas 2017, with an open commentary field and communication between bloggers and readers. Within this we find three female bloggers, who were at the top of the Norwegian blog list, ranging all active bloggers on Norwegian domains and tracking their traffic. The blog posts are studied with regards to disclosure statements, timing, and engagement through commentary field on the blog post. This is done by reading the blogs that promoted Storytel in the introduction and looking at blogglisten.no which 
is the site where daily reading numbers are published online in Norway. A thorough explanation of blogs selected for analysis is given in the next section.

The survey material in this paper is based on an online population survey, conducted in Sept-Oct 2016 by Opinion in Norway. The survey concerned book consumption in Norway and consisted of 48 open and closed-ended questions and had an $\mathrm{N}=1558$. Respondents were recruited from the online internet panel at Opinion, Norway. This survey was part of a larger research project regarding digitization and diversity in the Norwegian book industry. The survey included questions about who respondents listen to when looking for book recommendations was asked; with the option of listing bloggers they trust in this context. The data was weighed by gender, age, geographic location, and education to correct for deviation from the Norwegian population.

\section{Analysis and Discussion}

Respondents in the population survey was given the question "To what extent do you listen to the following people when deciding upon a new book to read?" The distribution looked like this:

As one can read, many respondents listen to their own preference, friends, family, and reviews, and far less to bloggers. These numbers show that bloggers have an influence on people when it comes to deciding upon what to read, but in line with the Decatur-study-interpersonal communication or own preference is still the largest source of influence. Despite this, opinion leadership is still influencing some respondents and on the follow-up question of which bloggers respondents listen to the blogger used for analysis in this study is the most frequently mentioned one with $24 \%$ of the mentions by those who report to read a blog on a regular basis.

The first blogger object for analysis, has promoted a healthy lifestyle with focus on exercise and healthy eating for over ten years. The blogger does this by using her own personal settings to do home exercise, cooks in her own kitchen and share glimpses of her personal life with family and friends. This blogger also shares makeup tips, styling and outfit inspiration and interior design tips. In 2015 she had above 45.000 readers on average throughout the year (Rakeng 2016). This blogger also had the highest income from her blog and was featured in traditional media above 600 times during 2015. This blogger had a continuing collaboration with Storytel from the end of 2015 until the end of 2017, with 17 posts about the service. This second blogger is an actress and television presenter. She is highly engaged in recycling, reuse of clothing, redesign of clothes and furniture. The second blogger has one blog post in the introduction of Storytel, and no further collaboration with the brand. There are no sources of readership numbers on this blog, and the commentary fields are closed. Any analysis of this blogger will therefore not be conducted. The third blog is a lifestyle blog with posts about life with children and the cancer battle of the blogger. The blogger provides styling tips and offers advice on marital life and parental guidance. The blog has an open commentary field, but only one blog post about Storytel. The collaborative blog post has only one comment on it, and after that the commentary field is closed. Furthermore, there are no readership 
numbers for the timeframe on this blog. Due to this, the blogger is excluded from further analysis, leaving the analysis to build upon one blogger that fit the requirement of being within the introduction of the service and have an open commentary field throughout the introduction to market period. The characteristics of opinion leaders as defined by Katz in 1957 build on expression of certain values, signalling of expertise and a social network that value the opinion and is of a certain size. With this, the first has polymorphic status with being an opinion leader on multiple areas of interest [29]. For readership and fit with the definition of opinion leadership this blogger has a social network of a certain size-being one of the largest in Norway. The blogger also express personification of healthy values and signals expertise on some areas. Based on this the first blogger fits with the definition of an opinion leader as defined by Katz (1957) with a polymorphic state as defined by Rogers [29].

In the interview with the marketing manager, the definition of a blogger was not mentioned as a guideline for choosing influencer marketing. "It all started with this one blogger writing about our service without any form of collaboration between us. She wrote about how she used audiobooks on our platform in her daily life and how it fit with her lifestyle. This blog post opened our eyes to that kind of marketing, and we were in the middle of planning our marketing mix to promote the service and build knowledge in the market about our service." As the marketing manager points out the use of influencers in the introduction was a coincidence. The background for choosing specific bloggers to collaborate with Storytel, the manager refers to target groups for the service and how this align with the readers of various blogs; "We depend on the association value with the blogger, and use them to reach a market segment that otherwise would be hard to access". This is in line with previous research on social media marketing $[12,36]$. Further, Storytel using the bloggers to create association value here, is typical of the change agent position. Here the blogger is the opinion leader and Storytel the change agent. As stated by Rogers "the change agent uses the opinion leader as their lieutenants in diffusion activities" [29, p. 27].

The decision to engage in a joint venture on marketing with the blogger was made after the blogger herself had promoted the service on the blog. This first blog post focused on the outfit of the day for the blogger, and in the last paragraph the blogger mentions using Storytel while driving home from a visit with her family. In total there are 41 comments on the post, where 23 of them are from the readers. There are no comments regarding Storytel as a service. Ten days after, the first blog post in collaboration with Storytel is posted. This shows how Storytel moves their relationship towards the blogger to one of change agent and opinion leader. Storytel as a change agent has gone through step five: establish intent to action by the opinion leader to utilize the interpersonal network to spread the innovation (Table 1). The post is clearly marked with the word "collaboration/ad", and the only narrative in the post is about Storytel. In total this post has 40 comments with 28 of them being from readers, and 12 of the comments are about books and the service. Table 2 shows the distribution of comments on all posts.

Table 2 also depicts how the blogger communicates with her readers. In line with Freberg et al. (2011) and Lu et al. (2014), the blogger is spreading the notion that some reciprocity has been made between the service and the blogger. As the 
Table 1 Distribution of answers to what extent respondents listen to various sources for decision making

\begin{tabular}{lllll}
$\begin{array}{l}\text { Very small } \\
\text { extent }(\%)\end{array}$ & $\begin{array}{l}\text { To a small } \\
\text { degree }(\%)\end{array}$ & Largely $(\%)$ & $\begin{array}{l}\text { To a very } \\
\text { large extent } \\
(\%)\end{array}$ & $\begin{array}{l}\text { Do not know/ } \\
\text { not applicable } \\
(\%)\end{array}$ \\
\hline 12 & 21 & 33 & 17 & 17 \\
13 & 23 & 31 & 16 & 18 \\
16 & 30 & 28 & 8 & 19 \\
18 & 22 & 22 & 9 & 29 \\
21 & 32 & 18 & 6 & 24 \\
11 & 23 & 34 & 15 & 17 \\
40 & 18 & 5 & 2 & 36 \\
2 & 5 & 29 & 48 & 16 \\
\hline
\end{tabular}

marketing manager points out "we did not have any goal for the reach of the blog post, but we sent out a brief to the agency for the blogger." These briefs have been made available for analysis purposes in this article. The briefs state facts about Storytel as a service, information about how the service works and other more specific information about promotional offers, specific hashtags to be used, preferences for pictures from the service or new releases on the service. This information is for the blogger to be accurate in the blog post and in the marketing towards readers, and by this Storytel again act as a change agent and utilize the second and fourth step of change agents according to Rogers [29]. The brief is explained this way from Storytel "Some bloggers want more information and direction in the brief than others. We make the brief specifically for each blog post and we follow through if the blogger has not given accurate information to the readers." By customizing the brief to each blogger and blog post, Storytel ensures that the autonomy of the bloggers is secured, but also that the creative constraints on the blog post are in line with the bloggers wishes and wants [1]. The brief also offered Storytel an opportunity to communicate clearly with the blogger about expectations to them, and for the blogger to build a transparent relationship with Storytel. This is in line with findings from Walden et al. [35] and the change agent position as described by Rogers [29].

In comparison, the Instagram posts are fewer and have substantially lower comments than the initial blog posts. The distribution looks like this (Table 3).

Furthermore, the Instagram-posts stopped during 2016, and did not include the December post. The requirement to post on Instagram and the blog simultaneously is optional and is removed after September 2016. The interaction between the blogger and reader is less on Instagram, and this could be because of a "swipe"-effect as the marketing manager of Storytel states. The easiness of swiping past an Instagram post is larger than for visiting a specific blog, and because of this Instagram might not be the best arena for promotional purposes. Another aspect of the Instagram interaction is the fact that only one of the five posts have any comments regarding a book or the service. This is in stark contrast to the same period and posts on the blog. In this, the two-step communication, and the role of Storytel as a change agent on Instagram is less effective or impactful than on the blog. Again, the marketing 


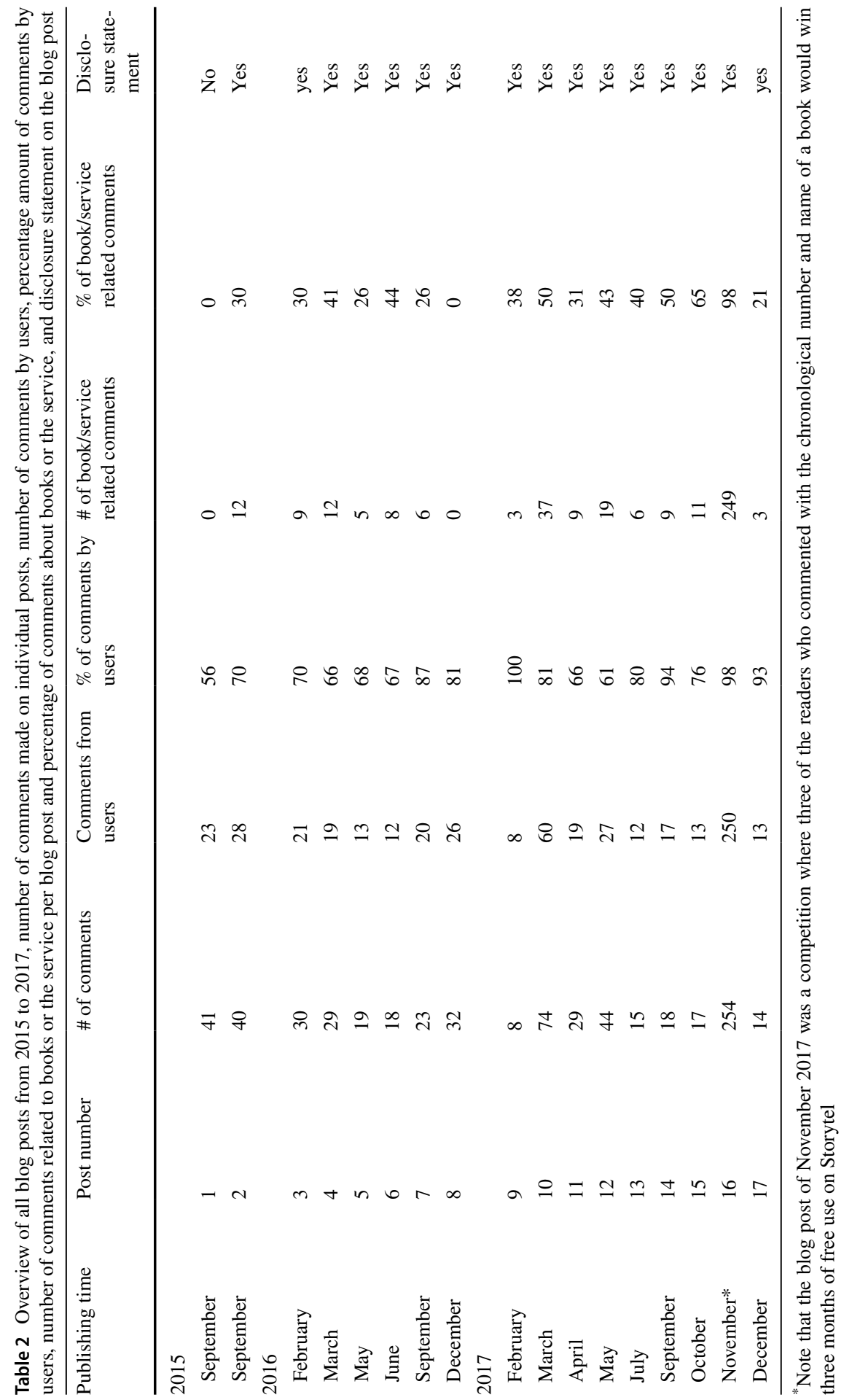


194

Publishing Research Quarterly (2021) 37:183-199

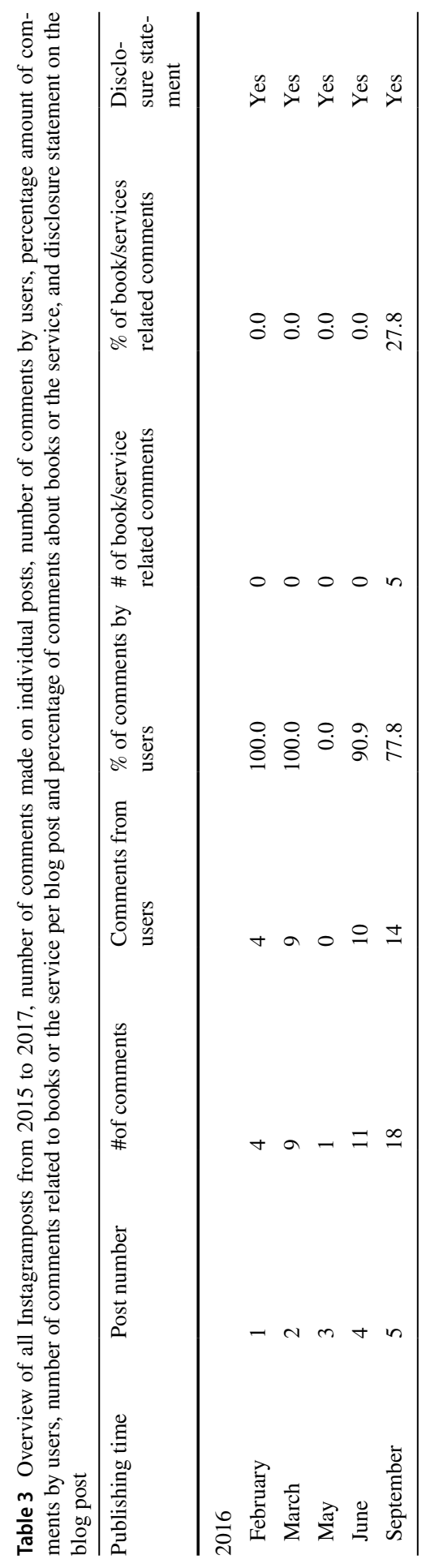

Springer 
manager of Storytel states that their initial effort was on the blogs and the agreement included Instagram more sporadically than permanent.

"In the introduction of our service we provided more information to bloggers than we do now" says the marketing manager. In the introduction phase Storytel emphasized how the bloggers lifestyle fit with the use of their service and how the service provides a new opportunity for readership than e-books and physical books can. Here Storytel is trying to conduct a displacement of known products and replace that with their [30]. With the brief the credibility of the bloggers could be diminished for some readers, but for others it can be a sign of honesty $[1,18]$. In the introduction of Storytel the quality of the message is also important, and the briefs could be seen as a way to create the conversation that is favourable toward the service. This is in line with Cheung et al. [4]. This is also in line with the change agent position of Rogers [29], as Storytel exchange information between the opinion leader and their target group that can increase the opinion leader's trustworthiness and credibility.

Previously, literature critics were subjected to scrutiny by literary scholars that spent long time analysing the literature based on well-known principles of literature [32]. Today, the increasing recommendations and critics from bloggers is based on subjective opinions and by that may become biased. Therefore, the freedom for bloggers to write about what they want in terms of literature was important in the introduction phase, as underlined by the marketing manager of Storytel. While bloggers have a joint agreement with Storytel, the selection of literature is based on bestseller-lists and/or commercial interests by the publisher or Storytel as a service. In addition to this, the literature recommended in the blogposts is not the primary focus - the service is. This is also underlined by the marketing manager at Storytel "When promoting Storytel, the bloggers are to promote the situation in everyday life where audiobooks fit in. Not necessarily specific books or authors, but when and where you can use our service". Although the bloggers are recommending literature, all of it is photographed within the app or on a device that runs Storytel's app. The marketing is pulled away from the literature itself to the service it is available on. In this perspective, one can argue that what bloggers are writing of literature critics has nothing to do with criticism although various books are recommended.

When evaluating how the bloggers are delivering users to the service, Storytel utilizes a mixed approach. "We measure the effect of the various marketing channels isolated and in interaction with each other. We look at how many sign-us we get through each blog post, but also how long each of those customers stay with us". For Storytel the collaboration with the blogger involved a continuous string of information and reminders about the service to the readers of the blog. In between the blog posts about Storytel, the blogger continues to write about other subjects and themes and by that maintain the polymorphic state of the blog [29]. Conversion of readers to subscribers to the service was one of the criteria for prolonging a collaboration with a blogger. As a measurement on this Storytel conducted brand knowledge surveys in the general market before and after collaboration with influencers and connected URL-redirections from the blogs to their website and sign-up. By this Storytel could follow the indirect and direct paths to knowledge and usage of the service and determine to what degree the blog post had any impact on diffusion of the service. With this Storytel can monitor the opinion leadership in the digital sphere and keep in 
control of the message about their brand [3, 29, 33]. The marketing manager underlines that the users acquired through the influencer strategy came faster than those from traditional marketing efforts, and that they were clearly from a different segment than traditional marketing. This also underlines the fact that change agents are.

\section{Conclusion}

Throughout the analysis and discussion, the overall research question is answered. There are several usages for bloggers and influencers in terms of marketing efforts in a launch, but it all must build upon good contracts and mutual understanding. Especially for a service connected to the creative industries one must look at lifestyle and compatibility more than for other industries to achieve credibility. Although the outset for the influencer marketing strategy of Storytel was accidental, the use of bloggers to promote the service follow the S-shaped curve for adoption. Storytel had a steep curve in the introduction phase, by targeting segments in a new way for traditional creative industries and then change the focus to retention of users rather than acquisition of new users. This study has shed light on the active usage of influencers to promote a service in the introduction phase and have little focus beyond what the service itself has defined as the introduction phase. By utilizing clear and transparent briefing notes to the bloggers, Storytel has successfully established relationships with various influencers and opinion leaders. Furthermore, the service has generated and built knowledge about their service and different usage situations of it. By utilizing eWOM, the diffusion process of Storytel in the introduction was more vertically oriented than horizontally, and by that the speed of adoption was rapid in the beginning and focus for Storytel could change from acquisition to retention quicker than through traditional marketing.

As for the sub-questions addressed here, we find that all bloggers have included a disclosure statement both in the text and in hashtags underneath pictures included at the beginning of each post. These are clear and visible for readers of the various posts and was also a requirement from Storytel in the briefs they gave bloggers. In terms of using the prominent bloggers in marketing efforts, Storytel is operating as a change agent and innovator [29]. Following this thought, the bloggers themselves act as change agents wishing to speed up the diffusion process of the innovation. They utilize their position with many followers to communicate information about the service more rapidly to enhance the chance of trial. Within this, the book review format is borrowed by the bloggers to promote the service and by that, the book review format is used to create a level of trustworthiness of each blog post.

Bloggers are effective in terms of easy segmentation, but retention of users due to blogger recruitment needs to be researched more. Although Storytel has grown quickly in the launch phase of the service, there is no guarantee that the users will stay with the service for a longer time. Storytel report a steady stream of users going in and out of their service, but they could not be linked to any blogger or marketing effort they made after initial trial subscription to the service. There is still a question left unanswered after this initial research-does bloggers provide more stable customers to a service over time? An answer to this should be sought out in the future. 
Acknowledgement This is a part of the Digitization and Diversity research project, conducted by the Centre for Creative Industries at BI Norwegian Business School, and is funder by the Norwegian Research Council under Grant Number: 247602.

Funding Open access funding provided by Norwegian Business School.

Open Access This article is licensed under a Creative Commons Attribution 4.0 International License, which permits use, sharing, adaptation, distribution and reproduction in any medium or format, as long as you give appropriate credit to the original author(s) and the source, provide a link to the Creative Commons licence, and indicate if changes were made. The images or other third party material in this article are included in the article's Creative Commons licence, unless indicated otherwise in a credit line to the material. If material is not included in the article's Creative Commons licence and your intended use is not permitted by statutory regulation or exceeds the permitted use, you will need to obtain permission directly from the copyright holder. To view a copy of this licence, visit http://creativecommons.org/licen ses/by/4.0\%.

\section{References}

1. Audrezet A, de Kerviler G, Moulard JG. Authenticity under threat: when social media influencers need to go beyond self-presentation. J Bus Res. 2017. https://doi.org/10.1016/j.jbusres.2018.07.008.

2. Aune, O.: Strømmer Til Lydboka - NRK Kultur Og Underholdning. NRK (2018). https://www.nrk. no/kultur/strommer-til-lydboka-1.14148493

3. Carr CT, Hayes RA. Social media: defining, developing, and divining. Atlantic J Commun. 2015. https://doi.org/10.1080/15456870.2015.972282.

4. Cheung CMK, Lee MKO, Rabjohn N. The impact of electronic word-of-mouth. Internet Res. 2008;18(3):229-47. https://doi.org/10.1108/10662240810883290.

5. De Veirman, M., Cauberghe, V., Hudders, L.: Marketing through instagram influencers: the impact of number of followers and product divergence on brand attitude. Int. J. Advertising 36(5), 798-828 (2017). https://doi.org/https://doi.org/10.1080/02650487.2017.1348035

6. Dhanesh GS, Duthler G. Relationship management through social media influencers: effects of followers' awareness of paid endorsement. Public Relations Review. 2019;45(3):101765. https://doi. org/10.1016/J.PUBREV.2019.03.002.

7. Digital Marketing Institute: 20 Key Influencer Marketing Facts to Learn From (2020). https://digit almarketinginstitute.com/en-us/blog/20-influencer-marketing-statistics-that-will-surprise-you

8. Doh S-J, Hwang J-S. How consumers evaluate EWOM (electronic word-of-mouth) messages. Cyberpsychol Behav. 2009;12(2):193-7. https://doi.org/10.1089/cpb.2008.0109.

9. Erkan I, Evans C. The influence of EWOM in social media on consumers' purchase intentions: an extended approach to information adoption. Comput Hum Behav. 2016;61:47-55. https://doi.org/10. 1016/j.chb.2016.03.003.

10. Forbrukertilsynet: Forbrukertilsynets Veileder for Merking Av Reklame i Sosiale Medier (2020). https://www.forbrukertilsynet.no/lov-og-rett/veiledninger-og-retningslinjer/veiledning-rekla me-some

11. Freberg K, Graham K, McGaughey K, Freberg LA. Who are the social media influencers? A study of public perceptions of personality. Public Relations Rev. 2011;37(1):90-2. https://doi.org/10. 1016/j.pubrev.2010.11.001.

12. Goodman MB, Booth N, Matic JA. Mapping and leveraging influencers in social media to shape corporate brand perceptions. Corporate Commun: Int J. 2011;16(3):184-91. https://doi.org/10.1108/ 13563281111156853.

13. Gupta P, Harris J. How E-WOM recommendations influence product consideration and quality of choice: a motivation to process information perspective. J Bus Res. 2010;63(9-10):1041-9. https:// doi.org/10.1016/j.jbusres.2009.01.015.

14. Hayes RA, Carr CT. Does being social matter? Effects of enabled commenting on credibility and brand attitude in social media. J Promot Manag. 2015;21(3):371-90. https://doi.org/10.1080/10496 491.2015.1039178. 
15. Hennig-Thurau T, Gwinner KP, Walsh G, Gremler DD. Electronic word-of-mouth via consumeropinion platforms: what motivates consumers to articulate themselves on the internet? J Interact Mark. 2004;18(1):38-52. https://doi.org/10.1002/DIR.10073.

16. Herring, S.C., Scheidt, L.A., Bonus, S., Wright, E.: Bridging the gap: a genre analysis of weblogs. In: Proceedings of the 37th Annual Hawaii International Conference on System Sciences (2004), 11. https://doi.org/https://doi.org/10.1109/HICSS.2004.1265271

17. Hsu C-L, Lin JC-C, Chiang H-S. The effects of blogger recommendation on customers' online shopping intentions. Internet Res. 2013;23(1):69-88. https://doi.org/10.1108/10662241311295782.

18. Hwang Y, Jeong SH. 'This is a sponsored blog post, but all opinions are my own': the effects of sponsorship disclosure on responses to sponsored blog posts. Comput Hum Behav. 2016;62:528-35. https://doi.org/10.1016/j.chb.2016.04.026.

19. Karlsen, S.G.: Bloggere Ga Lydbokboom I DN. Dagens Naringsliv, (2016). https://www.dn.no/ medier/boker/bloggere-ga-lydbokboom/1-1-5711754

20. Katz E. The two-step flow of communication: an up-to-date report on an hypothesis. Public Opin Q. 1957;21(1):61-78. https://doi.org/10.1086/266687.

21. Katz, E., Lazarsfeld, P.F.: Personal Influence: The Part Played by People in the Flow of Mass Communication. Transaction Publichers (Original works published by The Free Press in 1955)

22. Kelleher T, Miller BM. Organizational blogs and the human voice: relational strategies and relational outcomes. J Comput-Mediat Commun. 2017;11(2):395-414. https://doi.org/10.1111/j.10836101.2006.00019.x.

23. Kristensen L-B, Solvoll M. Digital payments for a digital generation: disruptive technology in book and local newspaper industries. Nordic J Media Stud. 2019;1(1):125-36.

24. Lee, D., Kartik, H., Nair, H.: Advertising content and consumer engagement on social media: evidence from facebook. Manag. Sci. 1-27 (2018). https://doi.org/https://doi.org/10.1287/mnsc.2017. 2902

25. Lu LC, Chang WP, Chang HH. Consumer attitudes toward blogger's sponsored recommendations and purchase intention: the effect of sponsorship type, product type, and brand awareness. Comput Hum Behav. 2014;34:258-66. https://doi.org/10.1016/j.chb.2014.02.007.

26. Norli, C., Ighanian, C.G., Pettersen, J., Hansen, F.: Forfattere Ut Mot Storforlagene: - Nå Er Det Nok! - VG." VG (2020). https://www.vg.no/rampelys/bok/i/x3P8kQ/forfattere-ut-mot-storforlag ene-naa-er-det-nok

27. Rakeng, T.R.: Tallene Som Vipper «Fotballfrue» Av Bloggtronen. Min Mote (2016). https://www. minmote.no/\#!/artikkel/23594816/tallene-som-vipper-fotballfrue-av-bloggtronen

28. Rambøll.: Kulturdepartementet: Utredning Om e-Bøker Og Utlån i Bibliotek (2015). https://www. regjeringen.no/contentassets/0d8914e29293412dbea9d976bde28732/rapport-om-utlan-av-e-bokeri-folkebibliotek.pdf

29. Rogers, E. M.: Diffusion of Innovations, 5th Edition. 5th Ed. Free Press (2003)

30. Rosenberg N. Factors affecting the diffusion of technology. Explor Econ Hist. 1972;10(1):3-33. https://doi.org/10.1016/0014-4983(72)90001-0.

31. Smith BG. The evolution of the blogger: blogger considerations of public relations-sponsored content in the blogosphere. Public Relat Rev. 2010;36(2):175-7. https://doi.org/10.1016/j.pubrev.2010. 02.006 .

32. Thompson, J.B.: Merchants of Culture: The Publishing Business in the Twenty-First Century. Second. Cambridge: Polity Press (2012)

33. Uzunoglu E, Kip SM. Brand communication through digital influencers: leveraging blogger engagement. Int J Inf Manage. 2014;34(5):592-602. https://doi.org/10.1016/J.IJINFOMGT.2014.04.007.

34. Vaage, O.F: Norsk Mediebarometer 2017. Statistisk Sentralbyrå. Statistisk Sentralbyrå (2018). http://www.ssb.no/kultur-og-fritid/artikler-og-publikasjoner/_attachment/262805?_ts=1540ea286c8

35. Walden JA, Bortree D, Distaso M. Reconsidering the public relations professional-blogger relationship: a coorientation study. Public Relat Rev. 2015;41:526-32. https://doi.org/10.1016/j.pubrev. 2015.06.002.

36. Wright DK, Hinson MD. How blogs and social media are changing public relations and the way it is practiced. Public Relations J. 2008;2(2):1-21.

37. Xifra J, Huertas A. Blogging PR: an exploratory analysis of public relations weblogs. Public Relat Rev. 2008;34(3):269-75. https://doi.org/10.1016/j.pubrev.2008.03.022. 
Publisher's Note Springer Nature remains neutral with regard to jurisdictional claims in published maps and institutional affiliations. 